University of Wollongong

Research Online

Australian Institute for Innovative Materials -

Papers

Australian Institute for Innovative Materials

$1-1-2016$

High pressure polymorphs and amorphization of upconversion host material $\mathrm{NaY}(\mathrm{WO} 4) 2$

\author{
Fang Hong \\ Center for High Pressure Science and Technology Advanced Research \\ Binbin Yue \\ Center for High Pressure Science and Technology Advanced Research \\ Zhenxiang Cheng \\ University of Wollongong, cheng@uow.edu.au \\ Martin Kunz \\ Lawrence Berkeley National Laboratory \\ Bin Chen \\ Center for High Pressure Science and Technology Advanced Research
}

See next page for additional authors

Follow this and additional works at: https://ro.uow.edu.au/aiimpapers

Part of the Engineering Commons, and the Physical Sciences and Mathematics Commons

Research Online is the open access institutional repository for the University of Wollongong. For further information contact the UOW Library: research-pubs@uow.edu.au 


\title{
High pressure polymorphs and amorphization of upconversion host material $\mathrm{NaY}(\mathrm{WO}) 2$
}

\author{
Abstract \\ The pressure effect on the structural change of upconversion host material $\mathrm{NaY}$ (WO4)2 was studied by \\ using in-situ synchrotron X-ray diffraction. A transition from the initial scheelite phase to the $\mathrm{M}$ - \\ fergusonite phase occurs near $10 \mathrm{GPa}$, and another phase transition is found near $27.5 \mathrm{GPa}$, which could \\ be an isostructural transition without symmetry change. The sample becomes amorphous when the \\ pressure is fully released from high pressure. This work demonstrates the possibility of synthesizing \\ various polymorph structures for non-linear optical applications with a high pressure, chemical doping, or \\ strained thin-film nanostructure process. \\ Disciplines \\ Engineering | Physical Sciences and Mathematics

\section{Publication Details} \\ Hong, F., Yue, B., Cheng, Z., Kunz, M., Chen, B. \& Mao, H. (2016). High pressure polymorphs and \\ amorphization of upconversion host material NaY(WO4)2. Applied Physics Letters, 109 (4), \\ 1041907-1-1041907-5.
}

\section{Authors}

Fang Hong, Binbin Yue, Zhenxiang Cheng, Martin Kunz, Bin Chen, and Ho-Kwang Mao 


\title{
High pressure polymorphs and amorphization of upconversion host material $\mathrm{NaY}\left(\mathrm{WO}_{4}\right)_{2}$
}

\author{
Fang Hong, ${ }^{1,2}$ Binbin Yue, ${ }^{1,2, a)}$ Zhenxiang Cheng, ${ }^{3}$ Martin Kunz, ${ }^{2}$ Bin Chen, ${ }^{1, a)}$ \\ and Ho-Kwang $\mathrm{Mao}^{1,4}$ \\ ${ }^{1}$ Center for High Pressure Science and Technology Advanced Research, 1690 Cailun Rd. Pudong, \\ Shanghai 201203, People's Republic of China \\ ${ }^{2}$ The Advanced Light Source, Lawrence Berkeley National Laboratory, 1 Cyclotron Rd, Berkeley, \\ California 94720, USA \\ ${ }^{3}$ Institute for Superconducting and Electronic Materials, Australian Institute of Innovative Materials, \\ University of Wollongong, Innovation Campus, Squires Way, North Wollongong, NSW 2500, Australia \\ ${ }^{4}$ Geophysical Laboratory, Carnegie Institution of Washington, Washington, DC 20015, USA
}

(Received 30 June 2016; accepted 19 July 2016; published online 29 July 2016)

The pressure effect on the structural change of upconversion host material $\mathrm{NaY}\left(\mathrm{WO}_{4}\right)_{2}$ was studied by using in-situ synchrotron X-ray diffraction. A transition from the initial scheelite phase to the M-fergusonite phase occurs near $10 \mathrm{GPa}$, and another phase transition is found near $27.5 \mathrm{GPa}$, which could be an isostructural transition without symmetry change. The sample becomes amorphous when the pressure is fully released from high pressure. This work demonstrates the possibility of synthesizing various polymorph structures for non-linear optical applications with a high pressure, chemical doping, or strained thin-film nanostructure process. Published by AIP Publishing.

[http://dx.doi.org/10.1063/1.4960104]

Photon upconversion is a nonlinear optical process where two or more low-energy photons have been sequentially absorbed by a material, and consequently, a highenergy light emission occurs. ${ }^{1}$ The crystal structure of the parent materials hosting the light emission centers is very important for their optical performance. ${ }^{2-5}$ Nanostructured $\mathrm{NaYF}_{4}$ has been used as a host for rare-earth-ion-luminescence upconversion, and these rare-earth-ion-doped $\mathrm{NaYF}_{4}$ nanocrystals have promising applications in the fields of bioimaging, sensing, cancer therapy, energy transfer, and even 3D display. ${ }^{6-11}$ The hexagonally structured $\mathrm{NaYF}_{4}$ has better upconversion efficiency than the cubic structure due to its higher light absorption efficiency. ${ }^{7}$ The $\mathrm{ABO}_{4}$-type oxide materials are expected to have more advantages for highpower laser materials due to their stable thermal conductivity, ${ }^{12}$ mechanical properties, light transparency, and easy access to large crystals. ${ }^{13-15}$ Lanthanide-doped $\mathrm{CaWO}_{4}$ has been studied widely for its bright light emission. ${ }^{5,16,17}$ However, the chemical valences of most lanthanide ions are $3+$, and these lanthanide ions locate inside the material interstitially, which limits the doping level and light emission effect. To enhance the upconversion performance, it is a good strategy to replace the $\mathrm{Ca}^{2+}$ by both $\mathrm{Na}^{+}$and $\mathrm{RE}^{3+}$ $\left(\mathrm{RE}=\right.$ rare-earth elements). Based on this idea, $\mathrm{NaY}\left(\mathrm{WO}_{4}\right)_{2}$ (or $\mathrm{Na}_{0.5} \mathrm{Y}_{0.5} \mathrm{WO}_{4}$ ) and $\mathrm{NaGd}\left(\mathrm{WO}_{4}\right)_{2}$ have been used as the host materials for solid-state laser materials. ${ }^{13-15,18-20}$ Unlike the structural instability of $\mathrm{NaYF}_{4}$ induced by lanthanide-doping, the crystal structures of $\mathrm{NaY}\left(\mathrm{WO}_{4}\right)_{2}$ and $\mathrm{NaGd}\left(\mathrm{WO}_{4}\right)_{2}$ are both very stable because the doped lanthanide ions have a similar ionic radius and therefore their substitution does not affect the crystal structure. This allows the $\mathrm{NaY}\left(\mathrm{WO}_{4}\right)_{2}$ and $\mathrm{NaGd}\left(\mathrm{WO}_{4}\right)_{2}$ to be excellent host materials. In addition, $\mathrm{AWO}_{4}$-type materials can be used as detector

${ }^{a}$ Electronic addresses: yuebb@hpstar.ac.cn and chenbin@hpstar.ac.cn materials for $\alpha$-ray and $\gamma$-rays and even for searching for dark matter or neutrinoless double beta decay. ${ }^{21,22}$

To tune the emission bands and/or achieve a much higher upconversion effect potential in these kinds of materials, it is important to find a method to control the crystal structure of the host materials. Here, we employed high pressure to study the structural evolution of $\mathrm{NaY}\left(\mathrm{WO}_{4}\right)_{2}$ and found that there are two phase transitions near $10 \mathrm{GPa}$ and $27.5 \mathrm{GPa}$, respectively. This work reveals possible high pressure polymorphic structures suitable for upconversion application and rare-event searches by using direct high pressure synthesis, chemical pressure introducing by smaller ion doping and strained structure-like epitaxial thin films.

A high-quality $\mathrm{NaY}\left(\mathrm{WO}_{4}\right)_{2}$ sample was synthesized by a solid state reaction method and ground into fine powder for this high pressure experiment. A compact sample was loaded in a Mao-type symmetric diamond anvil cell with a diamond culet of $300 \mu \mathrm{m}$. Silicone oil was used as a pressure medium. There are reports that the hydro-staticity of silicone oil is as good as the 4:1 methanol:ethanol mixture at low pressures to $\sim 20 \mathrm{GPa}$ and behaves as well as argon above $30 \mathrm{GPa}^{23,24} \mathrm{~A}$ stainless steel gasket was used, and a $100 \mu \mathrm{m}$ sample hole was drilled with a laser drilling system. The pressure was monitored by the R1-R2 line shift of Ruby. The in situ synchrotron micro X-ray diffraction experiment was carried out at room temperature on Beamline 12.2.2 at the Advanced Light Source at the Lawrence Berkeley National Laboratory and the incident X-ray wavelength was $0.4959 \AA$ A. Further details on the experiment are given Ref. 25.

The structural evolution of the $\mathrm{NaY}\left(\mathrm{WO}_{4}\right)_{2}$ sample under high pressure was examined by $\mathrm{X}$-ray diffraction and the results are presented in Figure 1. The X-ray diffraction pattern during the compression process is shown in Figure 1(a) while Figure 1(b) displays the decompression process. It is clear that there is a structural phase transition near $10 \mathrm{GPa}$ 

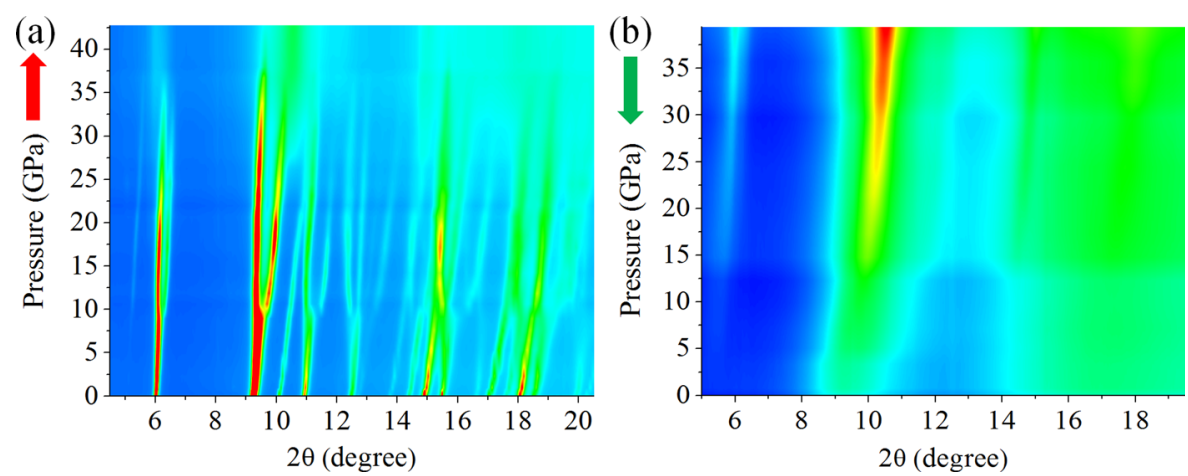

FIG. 1. The 2D x-ray diffraction mapping of $\mathrm{NaY}\left(\mathrm{WO}_{4}\right)_{2}$ at various pressures during compression and decompression, collected at room temperature. (a) The compression process: a clear structural phase transition is found near $10 \mathrm{GPa}$, evidenced by the appearance of extra peaks, and another phase transition starts near $27.5 \mathrm{GPa}$, indicated by an extra peak near $2 \theta=6^{\circ}$ and peak broadening; (b) decompression process: the peak intensity decreases as pressure releases and the sample becomes amorphous when the pressure is fully released.

during the compression process, where some extra peaks appear. In addition, an extra peak is found near $2 \theta=6^{\circ}$, and a shoulder peak appears near $2 \theta=10^{\circ}$ when the pressure reaches above $27.5 \mathrm{GPa}$. These changes suggest another phase transition. Under ambient conditions, the sample crystallizes in the scheelite-type tetragonal structure with a space group of $I 4_{1} / a$, and the lattice parameters are $\mathrm{a}=5.20479 \AA$ and $\mathrm{c}=11.27159 \AA$ according to the Rietveld refinement. These values are very similar to those of $\mathrm{CaWO}_{4}{ }^{26}$ Upon compression, all diffraction peaks of the tetragonal structure shift to higher angles, indicating that both the $a$ and $c$ axes become shorter under pressure. Some peaks shift faster than others, which suggests that the compressibility of the $a$ and $c$ axes differs from each other. Near $10 \mathrm{GPa}$, another phase appears and can be assigned to a monoclinic structure with a space group of $I 2 / a$, which is a typical M-fergusonite-type phase. A similar transition sequence from the scheelite phase to the M-fergusonite phase has also been observed in $\mathrm{CaWO}_{4}, \mathrm{SrWO}_{4}$, and $\mathrm{YLiF}_{4}{ }^{26,27}$ The diffraction peaks of the M-fergusonite-type phase shift to higher angles upon compression. At higher pressure (above $27.5 \mathrm{GPa}$ ), the peaks broaden and the intensity decreases as well. To some extent, the third phase is mixed with the M-fergusonite phase at a certain pressure range. As shown in Figure 1(b), during the decompression process, the third phase is maintained for a wide pressure range and does not go back to the M-fergusonite-type phase. However, the intensity continuously declines and the sample becomes amorphous when pressure is fully released.

Figure 2(a) displays the Rietveld refinement of x-ray diffraction patterns collected at three representative pressures. At $5.3 \mathrm{GPa}$, the structure is still in the tetragonal phase, marked as $\mathrm{T}$, which is the stable phase in ambient conditions. The peak position is well matched, and there is a relatively big difference between the experimental data and calculated data due to the higher contribution of some large grains. At $15.8 \mathrm{GPa}$, the structure already transfers to the M-fergusonite-type monoclinic structure, marked as M1. Due to the crack of big grains, the intensity difference between the experimental data and calculation data becomes much smaller than at $5.3 \mathrm{GPa}$. At $33.6 \mathrm{GPa}$, the M-fergusonite-type is mixed with another monoclinic phase with the same space group. The third phase is marked as M2 in the figure.
We tried to assign the third phase as the orthorhombic structure with space group Cmca, proposed by Botella et al. for the high pressure phase found in $\mathrm{CaWO}_{4}{ }^{28}$ However, the parameters provided in their work do not give a good refinement, even if we completely free the main structure parameters, because some extra peaks will appear at low diffraction angle region between $2 \theta=7^{\circ}$ and $2 \theta=9^{\circ}$. In our experimental data, there is no extra peak in that region. The situation is almost same when we assigned this high pressure phase to the Wolframite-type phase. ${ }^{29,30}$ Considering this character, we assume that the symmetry may not change, but the lattice parameter and atomic position do change. Then, we can get a good refinement result with two monoclinic structures (with the same symmetry I2/a) with different unit cell parameters. Hence, we proposed that the second high pressure polymorph of $\mathrm{NaY}\left(\mathrm{WO}_{4}\right)_{2}$ is still in a monoclinic structure with space group I2/a. Here, we cannot exclude another structural possibility due to the weak intensity and broad peak of the second high pressure phase, and a further study is required to examine the accurate structure. All the atomic
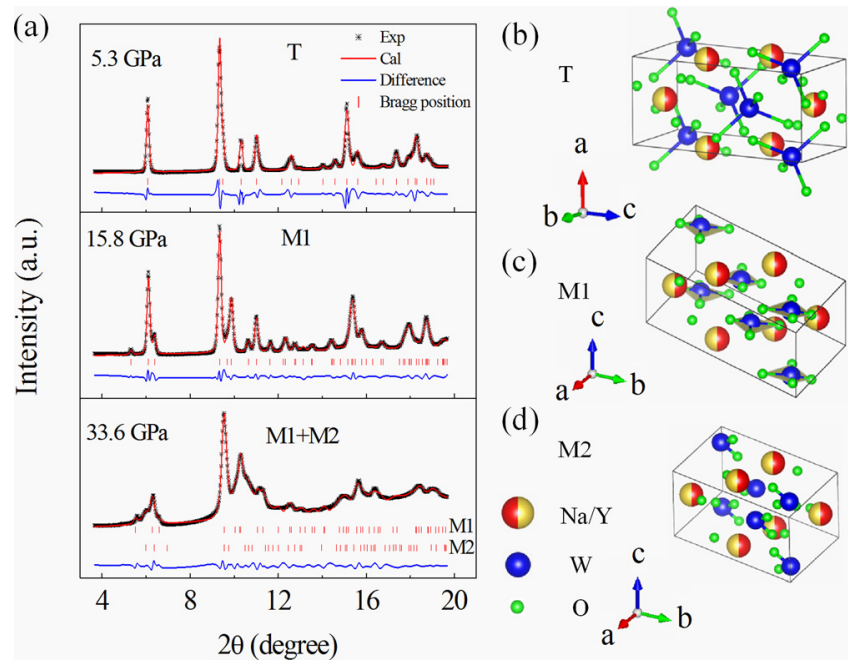

FIG. 2. The Rietveld refinement of the X-ray powder diffraction pattern at representative pressures and the atomic structure of three different phases. (a) At $5.3 \mathrm{GPa}$, the sample has a tetragonal structure, space group $I 4_{1} / a$; at $15.8 \mathrm{GPa}$, it changes into a monoclinic structure with space group $12 / \mathrm{a}$; at 33.6 GPa, an extra monoclinic phase appears with the same symmetry; (b-d) atomic structure of unit cell of tetragonal phase $(\mathrm{T})$, monoclinic phase 1 (M1), and monoclinic phase 2 (M2), respectively. 
TABLE I. Structural data of $\mathrm{NaY}\left(\mathrm{WO}_{4}\right)_{2}$ obtained from the Rietveld refinement of the X-ray powder diffraction pattern at representative pressures.

\begin{tabular}{|c|c|c|c|c|c|}
\hline $\begin{array}{l}5.3 \mathrm{GPa} \\
\mathrm{T}\left(I 4_{1} / a\right) \\
\end{array}$ & & $\begin{array}{c}\mathrm{a} \\
5.162(8)\end{array}$ & $\begin{array}{c}\mathrm{b} \\
5.162(8)\end{array}$ & $\begin{array}{c}c \\
11.032(7)\end{array}$ & \\
\hline & Site & $\mathrm{x}$ & $\mathrm{y}$ & z & Occupancy \\
\hline $\mathrm{Na}$ & $4 b$ & 0 & 0.25 & 0.625 & 0.5 \\
\hline $\mathrm{Y}$ & $4 b$ & 0 & 0.25 & 0.625 & 0.5 \\
\hline $\mathrm{W}$ & $4 a$ & 0 & 0.25 & 0.125 & 1 \\
\hline $\mathrm{O}$ & $16 f$ & $0.2118(6)$ & $-0.1068(1)$ & $-0.0076(4)$ & 1 \\
\hline $15.8 \mathrm{GPa}$ & & $\mathrm{a}$ & $b$ & $\mathrm{c}$ & Beta \\
\hline \multirow[t]{2}{*}{$\operatorname{M1}(I 2 / a)$} & & 4.908 (1) & $10.693(4)$ & $5.183(7)$ & $94.553(9)$ \\
\hline & Site & $\mathrm{x}$ & $\mathrm{y}$ & z & Occupancy \\
\hline $\mathrm{Na}$ & $4 \mathrm{e}$ & 0.25 & $0.6556(9)$ & 0 & 0.5 \\
\hline $\mathrm{Y}$ & $4 \mathrm{e}$ & 0.25 & $0.6556(9)$ & 0 & 0.5 \\
\hline $\mathrm{W}$ & $4 \mathrm{e}$ & 0.25 & $0.1321(1)$ & 0 & 1 \\
\hline $\mathrm{O} 1$ & $8 \mathrm{f}$ & $0.4395(7)$ & $0.0474(4)$ & $0.1030(9)$ & 1 \\
\hline $\mathrm{O} 2$ & $8 \mathrm{f}$ & $0.5477(7)$ & $0.2991(0)$ & $0.6878(2)$ & 1 \\
\hline $33.6 \mathrm{GPa}$ & & $\mathrm{a}$ & $\mathrm{b}$ & $\mathrm{c}$ & Beta \\
\hline \multirow[t]{2}{*}{$\mathrm{M} 2(I 2 / a)$} & & $5.929(3)$ & $8.161(3)$ & $5.417(3)$ & $79.391(1)$ \\
\hline & Site & $\mathrm{x}$ & $\mathrm{y}$ & $\mathrm{z}$ & Occupancy \\
\hline $\mathrm{Na}$ & $4 \mathrm{e}$ & 0.25 & $0.5389(6)$ & 0 & 0.5 \\
\hline $\mathrm{Y}$ & $4 \mathrm{e}$ & 0.25 & $0.5389(6)$ & 0 & 0.5 \\
\hline $\mathrm{W}$ & $4 \mathrm{e}$ & 0.25 & $0.1135(6)$ & 0 & 1 \\
\hline $\mathrm{O} 1$ & $8 f$ & $-0.0839(6)$ & $0.1807(5)$ & $-0.4452(9)$ & 1 \\
\hline $\mathrm{O} 2$ & $8 \mathrm{f}$ & $0.9619(5)$ & $-0.2184(2)$ & $0.5939(9)$ & 1 \\
\hline
\end{tabular}

structures of these three phases are demonstrated in Figures 2(b)-2(d), respectively. Meanwhile, the main structure parameters based on Rietveld refinement results are listed in Table I (shown at the end of this manuscript for review).

The detailed structural information at different pressures is provided in Figure 3. The pressure dependent lattice parameters are plotted in Figure 3(a). Consistent with the discussion mentioned above, the lattice parameters of the $\mathrm{T}$ phase decrease monotonously upon high pressure but they show different compressibilities. The $c / a$ ratio decreases with pressure (not shown), suggesting that the longer $c$ axis is more easily compressed than the short $a$ axis. When the pressure exceeds $10 \mathrm{GPa}$, the M1 phase appears and the previous $\mathrm{c}$ axis in the $\mathrm{T}$ phase becomes a $c$ axis in the M1 phase due to the symmetry change. All three lattice parameters in the M1 phase show a monotonously declining trend with pressure. The trend changes a little bit for the $b$ axis when the sample enters into the M2 phase, which shows a positive dependence at first for a few pressure points and then decreases with pressure. The pressure dependent volume change is given in Figure 3(b) (red solid cubic: T phase; blue solid circle: M1 phase; magma solid triangle: M2 phase; and olive green open circle: mixed M1 and M2 phase). The volumes become smaller and smaller with increasing pressure. Unlike a previous study on $\mathrm{CaWO}_{4}$, we found a volume discontinuity near $10 \mathrm{GPa}$, where the T-M1 phase transition occurs. ${ }^{26}$ For the M1-M2 phase transition, no volume discontinuity is observed. The pure M2 phase's volume is a little bit bigger than the pure M1 phase at the same pressure. It is noticed that the real volume (per unit) of the sample contributed by both M1 and M2 phases does not change too much above the M1-M2 phase transition pressure. This could be a signature of an amorphous process in the high pressure range. Pressure-driven volume anomaly has been observed in amorphous selenium and the local topological fluctuations during phase transition are proposed to be the origin of the anomaly. ${ }^{31}$ There is also a similar pressure-driven volume anomaly in amorphous silica and the network flexibility hypothesis could explain this anomaly. ${ }^{32}$ We speculate that the network flexibility at high pressure is responsible for the observed volume anomaly and finally allows the occurrence of amorphization. The disruption of some $\mathrm{W}-\mathrm{O}$ bonds in M2 phase, as shown in Figure 2(d), already shows some signatures of amorphization. This is very similar to the case of
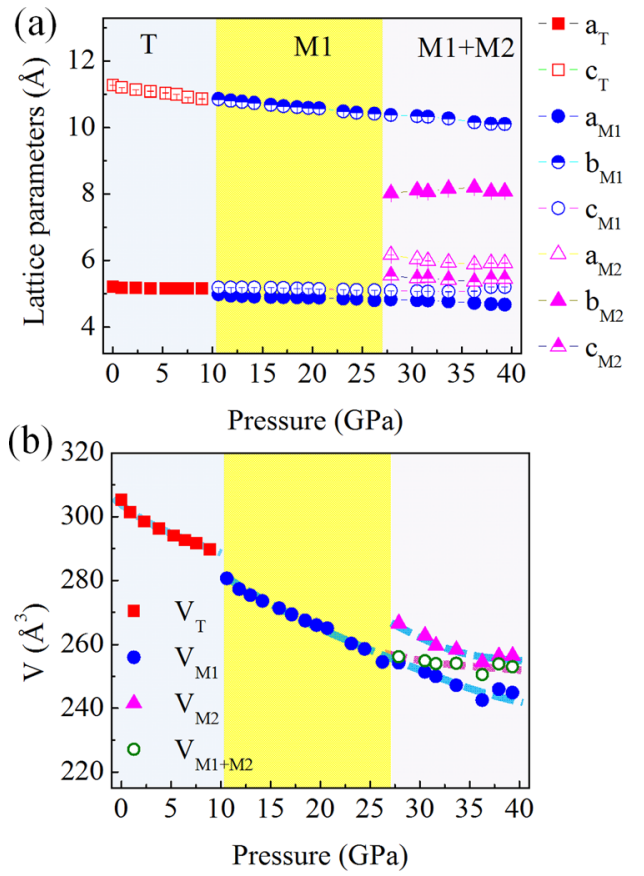
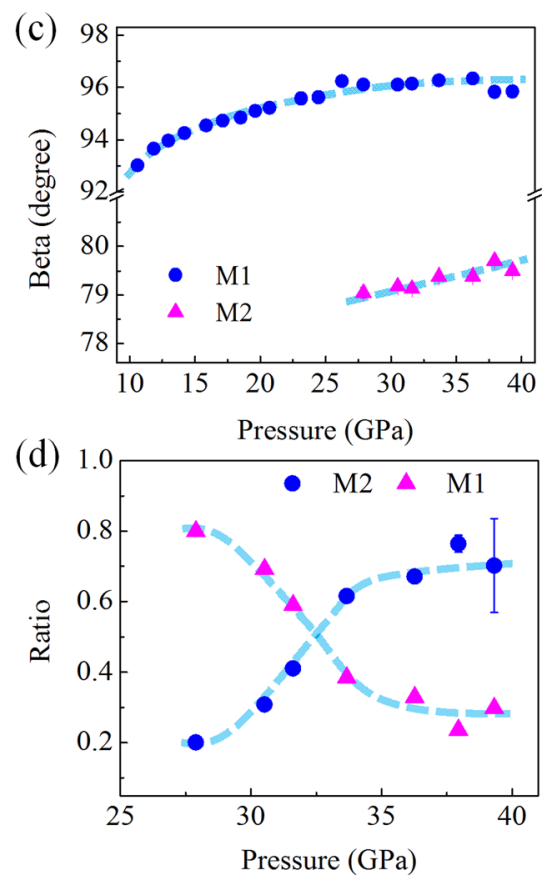

FIG. 3. The pressure dependent structural parameters obtained from the Rietveld refinement of the X-ray powder diffraction patterns. (a) The lattice parameter change under high pressure, (b) volume change, (c) the beta angle evolution of monoclinic structure from $10 \mathrm{GPa}$ to $40 \mathrm{GPa}$, and (d) ratio of M1 and M2 phases above $27.5 \mathrm{GPa}$. 
pressure-induced amorphous $\mathrm{Ta}_{2} \mathrm{O}_{5}$, in which the disruption of some weak-bonds initiates the amorphization. ${ }^{33}$ Further work is required to determine an accurate crystal structure and clarify the volume anomaly. Figure 3(c) shows the beta angle of two monoclinic phases. The beta angle of the M1 phase is larger than $90^{\circ}$, and the beta angle of the M2 phase is smaller than $90^{\circ}$, but both of them show positive pressure dependence. The beta angle trend of the M1 phase is highly similar to the calculated result on the high pressure structure of $\mathrm{CaWO}_{4}{ }^{28}$ The ratio of these two monoclinic phases is displayed in Figure 3(d). The ratio of the M2 phase increases sharply below $35 \mathrm{GPa}$ and there is still a small portion of the M1 phase near $40 \mathrm{GPa}$, above which it is supposed to be a pure M2 phase and then the sample could enter into an amorphous state.

The M-fergusonite-type monoclinic (M1 phase) tungstates are found to exist in ambient conditions, such as $\mathrm{HgWO}_{4}$ and $\mathrm{KY}\left(\mathrm{WO}_{4}\right)_{2}{ }^{34-38}$ In lanthanide-doped monoclinic $\mathrm{KY}\left(\mathrm{WO}_{4}\right)_{2}$, highly efficient pulse laser operation has been achieved with a diode-pump. ${ }^{37,39}$ This precludes the possibility to continuously tune the crystal structure of $\mathrm{NaY}\left(\mathrm{WO}_{4}\right)_{2}$ by chemical doping via the introduction of different amounts of $\mathrm{K}$ or $\mathrm{Hg}$ at ambient conditions, which could boost the exploration of host materials for highly efficient upconversion and solid state lasers. In our study, even without $\mathrm{K}$ or $\mathrm{Hg}$ doping, the structure of $\mathrm{NaY}\left(\mathrm{WO}_{4}\right)_{2}$ can still be tuned continuously by external pressure, which provides another efficient way to do the same work. Amorphous materials have also been used as the host materials for upconversion and solid state lasers, such as amorphous silicon, $\mathrm{Al}_{2} \mathrm{O}_{3}$, and $\mathrm{Y}_{2} \mathrm{O}_{3} \cdot{ }^{40-43}$ It is known that local crystal field affects the upconversion efficiency and it is very important to understand its effect on the luminescent properties. One solution is to synthesize both the bulk and amorphous host materials and make a comparative study. In some cases, the amorphous host materials perform better than the crystalline bulk materials, which make amorphous host materials more promising in some areas. ${ }^{40,44}$ Taking $\mathrm{Y}_{2} \mathrm{O}_{3}$, for example, the pulsed laser induces an amorphous surface layer on the $\mathrm{Y}_{2} \mathrm{O}_{3}$ nanocrystals and a strong blue light emission is observed when it is pumped by a $976 \mathrm{~nm}$ diode laser, which is ten times stronger than that of pure crystalline $\mathrm{Y}_{2} \mathrm{O}_{3}{ }^{40}$ Here, the amorphous $\mathrm{NaY}\left(\mathrm{WO}_{4}\right)_{2}$ was obtained by compression and the structure maintained at ambient conditions, suggesting that it could be a promising amorphous host material. Future luminescent studies based on this amorphous material could help us to understand the crystal field effect and provide more information on how to design high-performance optical materials for nonlinear optics.

The crystal structure of upconversion host material $\mathrm{NaY}\left(\mathrm{WO}_{4}\right)_{2}$ under high pressure has been studied via synchrotron x-ray diffraction at room temperature. At ambient conditions, $\mathrm{NaY}\left(\mathrm{WO}_{4}\right)_{2}$ is in the form of scheelite-type tetragonal structure. There is a structural phase transition, starting near $10 \mathrm{GPa}$, from the scheelite phase to the M-fergusonite phase. The M-fergusonite-type monoclinic structure is stable up to $27.5 \mathrm{GPa}$, above which the sample undergoes another structural phase transition. The second phase transition is proposed to be an isostructure transition without symmetry change, but the unit cells are quite different. The sample becomes amorphous when pressure returns to ambient conditions, which could be explained by the volume anomaly of high pressure monoclinic structures. This work provides guidance on tuning the crystal structure of host materials for photon upconversion by using high pressure technique. This may inspire the chemical or physical synthesis of high pressure polymorphs by using direct high pressure synthesis, chemical doping, and strain engineering, and brighten the future applications of these kinds of host materials.

The authors acknowledge support from the NSAF (Grant No. U1530402). F.H. and B.B.Y. acknowledge the usage of beam time at Beamline 12.2.2 at the Advanced Light Source in Lawrence Berkeley National Laboratory. All authors thank Freyja O'Toole for her careful revision of the manuscript.

${ }^{1}$ F. Auzel, Chem. Rev. 104, 139-173 (2004).

${ }^{2}$ M. Haase and H. Schaefer, Angew. Chem., Int. Ed. 50, 5808-5829 (2011).

${ }^{3}$ F. Wang, R. Deng, J. Wang, Q. Wang, Y. Han, H. Zhu, X. Chen, and X. Liu, Nat. Mater. 10, 968-973 (2011).

${ }^{4}$ H. Wang, C. Tu, Z. You, F. Yang, Y. Wei, Y. Wang, J. Li, Z. Zhu, G. Jia, and X. Lu, Appl. Phys. B 88, 57-60 (2007).

${ }^{5}$ J. H. Chung, S. Y. Lee, K. B. Shim, and J. H. Ryu, Appl. Phys. Express 5, 052602 (2012).

${ }^{6}$ B. Zhou, B. Shi, D. Jin, and X. Liu, Nat. Nanotechnol. 10, 924-936 (2015).

${ }^{7}$ F. Wang, Y. Han, C. S. Lim, Y. Lu, J. Wang, J. Xu, H. Chen, C. Zhang, M. Hong, and X. Liu, Nature 463, 1061-1065 (2010).

${ }^{8}$ F. Wang and X. Liu, Chem. Soc. Rev. 38, 976-989 (2009).

${ }^{9}$ J. Zhou, Z. Liu, and F. Li, Chem. Soc. Rev. 41, 1323-1349 (2012).

${ }^{10}$ F. Wang and X. Liu, J. Am. Chem. Soc. 130, 5642 (2008).

${ }^{11}$ W. Zou, C. Visser, J. A. Maduro, M. S. Pshenichnikov, and J. C. Hummelen, Nat. Photonics 6, 560-564 (2012).

${ }^{12}$ A. Senyshyn, H. Kraus, V. B. Mikhailik, and V. Yakovyna, Phys. Rev. B 70, 214306 (2004).

${ }^{13}$ F. Song, L. Han, H. Tan, J. Su, J. Yang, J.-g. Tian, G.-y. Zhang, Z.-x. Cheng, and H.-c. Chen, Opt. Commun. 259, 179-186 (2006).

${ }^{14}$ M. D. Serrano, C. Cascales, X. Han, C. Zaldo, A. Jezowski, P. Stachowiak, N. Ter-Gabrielyan, V. Fromzel, and M. Dubinskii, PLoS One 8, e59381 (2013).

${ }^{15}$ J. Liu, H. Zhang, J. Wang, and V. Petrov, Opt. Express 15, 12900-12904 (2007).

${ }^{16}$ W. Xu, X. Gao, L. Zheng, P. Wang, Z. Zhang, and W. Cao, Appl. Phys. Express 5, 072201 (2012).

${ }^{17}$ W. Xu, Z. Zhang, and W. Cao, Opt. Lett. 37, 4865-4867 (2012).

${ }^{18}$ X. Yu, Y. Qin, M. Gao, L. Duan, Z. Jiang, L. Gou, P. Zhao, and Z. Li, J. Lumin. 153, 1-4 (2014)

${ }^{19}$ Z. Wang, Y. Li, Q. Jiang, H. Zeng, Z. Ci, and L. Sun, J. Mater. Chem. C 2, 4495-4501 (2014).

${ }^{20}$ Y. Wang, W. Xu, S. Cui, S. Xu, Z. Yin, H. Song, P. Zhou, X. Liu, L. Xu, and H. Cui, Nanoscale 7, 1363-1373 (2015).

${ }^{21}$ Y. G. Zdesenko, F. T. Avignone Iii, V. B. Brudanin, F. A. Danevich, V. V. Kobychev, B. N. Kropivyansky, S. S. Nagorny, V. I. Tretyak, and T. Vylov, Astropart. Phys. 23, 249-263 (2005).

${ }^{22}$ M. v. Sivers, M. Clark, P. C. F. Di Stefano, A. Erb, A. Gütlein, J.-C. Lanfranchi, A. Münster, P. Nadeau, M. Piquemal, W. Potzel, S. Roth, K. Schreiner, R. Strauss, S. Wawoczny, M. Willers, and A. Zöller, J. Appl. Phys. 118, 164505 (2015).

${ }^{23}$ Y. Shen, R. S. Kumar, M. Pravica, and M. F. Nicol, Rev. Sci. Instrum. 75, 4450-4454 (2004).

${ }^{24}$ S. Klotz, J. C. Chervin, P. Munsch, and G. L. Marchand, J. Phys. D: Appl. Phys. 42, 075413 (2009).

${ }^{25}$ M. Kunz, A. A. MacDowell, W. A. Caldwell, D. Cambie, R. S. Celestre, E. E. Domning, R. M. Duarte, A. E. Gleason, J. M. Glossinger, N. Kelez, D. W. Plate, T. Yu, J. M. Zaug, H. A. Padmore, R. Jeanloz, A. P. Alivisatos, and S. M. Clark, J. Synchrotron Radiat. 12, 650-658 (2005).

${ }^{26}$ D. Errandonea, J. Pellicer-Porres, F. J. Manjón, A. Segura, C. Ferrer-Roca, R. S. Kumar, O. Tschauner, P. Rodríguez-Hernández, J. López-Solano, S. Radescu, A. Mujica, A. Muñoz, and G. Aquilanti, Phys. Rev. B 72, 174106 (2005). 
${ }^{27}$ A. Grzechnik, K. Syassen, I. Loa, M. Hanfland, and J. Y. Gesland, Phys. Rev. B 65, 104102 (2002).

${ }^{28}$ P. Botella, R. Lacomba-Perales, D. Errandonea, A. Polian, P. RodríguezHernández, and A. Muñoz, Inorg. Chem. 53, 9729-9738 (2014).

${ }^{29}$ R. Lacomba-Perales, D. Errandonea, D. Martinez-Garcia, P. RodriguezHernandez, S. Radescu, A. Mujica, A. Munoz, J. C. Chervin, and A. Polian, Phys. Rev. B 79, 094105 (2009).

${ }^{30}$ J. Ruiz-Fuertes, S. Lopez-Moreno, D. Errandonea, J. Pellicer-Porres, R. Lacomba-Perales, A. Segura, P. Rodriguez-Hernandez, A. Munoz, A. H. Romero, and J. Gonzalez, J. Appl. Phys. 107, 083506 (2010).

${ }^{31}$ H. Liu, L. Wang, X. Xiao, F. De Carlo, J. Feng, H.-k. Mao, and R. J. Hemley, Proc. Natl. Acad. Sci. U.S.A. 105, 13229-13234 (2008).

${ }^{32}$ M. W. Andrew, A. S. Lucy, T. Kostya, P. B. Richard, O. H. W. Toby, T. D. Martin, P. T. Richard, T. T. Ilian, and A. W. Stephen, J. Phys.: Condens. Matter 19, 275210 (2007).

${ }^{33}$ X. Lü, Q. Hu, W. Yang, L. Bai, H. Sheng, L. Wang, F. Huang, J. Wen, D. J. Miller, and Y. Zhao, J. Am. Chem. Soc. 135, 13947-13953 (2013).

${ }^{34}$ F. J. Manjón, J. López-Solano, S. Ray, O. Gomis, D. Santamaría-Pérez, M. Mollar, V. Panchal, D. Errandonea, P. Rodríguez-Hernández, and A. Muñoz, Phys. Rev. B 82, 035212 (2010).

${ }^{35}$ K. K. Rasu, A. Durairajan, D. Balaji, and S. M. Babu, AIP Conf. Proc. 1665, 140007 (2015).
${ }^{36}$ P. A. Loiko, V. I. Dashkevich, S. N. Bagaev, V. A. Orlovich, A. S. Yasukevich, K. V. Yumashev, N. V. Kuleshov, E. B. Dunina, A. A. Kornienko, S. M. Vatnik, and A. A. Pavlyuk, J. Lumin. 153, 221-226 (2014).

${ }^{37}$ E. Castellano-Hernandez, X. Han, M. Rico, L. Roso, C. Cascales, and C. Zaldo, Opt. Express 23, 11135-11140 (2015).

${ }^{38}$ R. Cattoor, I. Manek-Hoenninger, D. Rytz, L. Canioni, and M. Eichhorn, Opt. Lett. 39, 6407-6410 (2014).

${ }^{39}$ T. C. Schratwieser, C. G. Leburn, and D. T. Reid, Opt. Lett. 37, 1133-1135 (2012).

${ }^{40}$ C. B. Zheng, Y. Q. Xia, F. Qin, Y. Yua, J. P. Miao, Z. G. Zhang, and W. W. Cao, Chem. Phys. Lett. 509, 29-32 (2011).

${ }^{41}$ Y. Y. Cheng, B. Fueckel, R. W. MacQueen, T. Khoury, R. G. C. R. Clady, T. F. Schulze, N. J. Ekins-Daukes, M. J. Crossley, B. Stannowski, K. Lips, and T. W. Schmidt, Energy Environ. Sci. 5, 6953-6959 (2012).

${ }^{42}$ L. Agazzi, K. Worhoff, and M. Pollnau, J. Phys. Chem. C 117, 6759-6776 (2013).

${ }^{43}$ J. de Wild, A. Meijerink, J. K. Rath, W. G. J. H. M. van Sark, and R. E. I. Schropp, Sol. Energy Mater. 94, 1919-1922 (2010).

${ }^{44}$ G. S. Qin, W. P. Qin, C. F. Wu, S. H. Huang, J. S. Zhang, S. Z. Lu, D. Zhao, and H. Q. Liu, J. Appl. Phys. 93, 4328-4330 (2003). 